University of Nebraska - Lincoln DigitalCommons@University of Nebraska - Lincoln

Faculty Publications, Department of Physics and

Astronomy

Research Papers in Physics and Astronomy

2011

On the relation between the activation energy for electron attachment reactions and the size of their thermal rate coefficients

H. Hotop

M.-W. Ruf

J. Kopyra

T. M. Miller

I. I. Fabrikant

Follow this and additional works at: https://digitalcommons.unl.edu/physicsfacpub

This Article is brought to you for free and open access by the Research Papers in Physics and Astronomy at DigitalCommons@University of Nebraska -

Lincoln. It has been accepted for inclusion in Faculty Publications, Department of Physics and Astronomy by an authorized administrator of

DigitalCommons@University of Nebraska - Lincoln. 


\title{
On the relation between the activation energy for electron attachment reactions and the size of their thermal rate coefficients
}

\author{
H. Hotop, ${ }^{1, a)}$ M.-W. Ruf, ${ }^{1}$ J. Kopyra, ${ }^{2}$ T. M. Miller, ${ }^{3}$ and I. I. Fabrikant ${ }^{1,4,5}$ \\ ${ }^{1}$ Fachbereich Physik, Technische Universität Kaiserslautern, D-67653 Kaiserslautern, Germany \\ ${ }^{2}$ Chemistry Department, University in Siedlce, 08-110 Siedlce, Poland \\ ${ }^{3}$ Air Force Research Laboratory, Hanscom Air Force Base, Bedford, Massachusetts 01731-3010, USA \\ ${ }^{4}$ Department of Physics and Astronomy, University of Nebraska, Lincoln, Nebraska 68588-0111, USA \\ ${ }^{5}$ Department of Physics and Astronomy, The Open University, Walton Hall, Milton Keynes MK7 6AA, UK
}

(Received 10 December 2010; accepted 6 January 2011; published online 8 February 2011)

\begin{abstract}
Rate coefficients $k(T)$ for dissociative electron attachment (DEA) to molecules in many cases exhibit a more or less strong rise with increasing temperature $T$ (the electron temperature $T_{\mathrm{e}}$ and the molecular temperature $T_{\mathrm{G}}$ are assumed to be in thermal equilibrium, i.e., $T=T_{\mathrm{e}}=T_{\mathrm{G}}$ ). This rise is frequently modeled by the Arrhenius equation $k(T)=k_{\mathrm{A}} \exp \left[-E_{\mathrm{a}} /\left(k_{\mathrm{B}} T\right)\right]$, and an activation energy $E_{\mathrm{a}}$ is deduced from fits to the experimental data $k(T)$. This behavior reflects the presence of an energy barrier for the anion on its path to the dissociated products. In a recent paper [J. Kopyra, J. Wnorowska, M. Foryś, and I. Szamrej, Int. J. Mass Spectrom. 268, 60 (2007)] it was suggested that the size of the rate coefficients for DEA reactions at room temperature exhibits an exponential dependence on the activation energy, i.e., $k\left(E_{\mathrm{a}} ; T \approx 300 \mathrm{~K}\right)=k_{1} \exp \left[-E_{\mathrm{a}} / E_{0}\right]$. More recent experimental data for molecules with high barriers [T. M. Miller, J. F. Friedman, L. C. Schaffer, and A. A. Viggiano, J. Chem. Phys. 131, 084302 (2009)] are compatible with such a correlation. We investigate the validity and the possible origin of this dependence by analyzing the results of R-matrix calculations for temperature-dependent rate coefficients of exothermic DEA processes with intermediate barrier toward dissociation. These include results for model systems with systematically varied barrier height as well as results of molecule-specific calculations for $\mathrm{CH}_{3} \mathrm{Cl}, \mathrm{CH}_{3} \mathrm{Br}, \mathrm{CF}_{3} \mathrm{Cl}$, and $\mathrm{CH}_{2} \mathrm{Cl}_{2}$ (activation energies above $0.2 \mathrm{eV}$ ) involving appropriate molecular parameters. A comparison of the experimental and theoretical results for the considered class of molecules (halogenated alkanes) supports the idea that the exponential dependence of $k(T=300 \mathrm{~K})$ on the activation energy reflects a general phenomenon associated with Franck-Condon factors for getting from the initial neutral vibrational levels to the dissociating final anion state in a direct DEA process. Cases are discussed for which the proposed relation does not apply. () 2011 American Institute of Physics. [doi:10.1063/1.3548874]
\end{abstract}

\section{INTRODUCTION}

In a recent paper, ${ }^{1}$ the validity of the Arrhenius equation $\left(E_{\mathrm{a}}=\right.$ activation energy $)$

$$
k(T)=k_{\mathrm{A}} \exp \left[\frac{-E_{\mathrm{a}}}{k_{\mathrm{B}} T}\right]
$$

for describing the temperature dependence of thermal rate coefficients $k(T)$ for dissociative electron attachment (DEA) reactions

$$
\mathrm{e}^{-}(E)+X Y \rightarrow X+Y^{-}
$$

has been theoretically investigated. For the case of exothermic DEA with intermediate barrier toward dissociation - the main topic of the present paper-it was shown that Eq. (1) holds only over a finite intermediate range of temperatures. At very low temperatures, an essentially constant value $k_{0}$ $\equiv k(T \rightarrow 0)$ is reached (it is assumed throughout this paper that the electron temperature $T_{\mathrm{e}}$ and the molecular gas temperature $T_{\mathrm{G}}$ are in thermal equilibrium, i.e., $T=T_{\mathrm{e}}=T_{\mathrm{G}}$ ); this

\footnotetext{
a) Author to whom correspondence should be addressed. Electronic mail: hotop@physik.uni-kl.de.
}

(molecule-specific) constant $k_{0}$ represents the value for the DEA rate coefficient involving molecules in the vibrational ground state at near-zero electron energy. Toward higher temperatures a more or less strong rise of the rate coefficient with Arrhenius-type behavior, Eq. (1), is observed, and at very high temperatures the calculated rate coefficients tend to saturate. As one experimental example for such a behavior is shown in Fig. 1, the case $X Y=\mathrm{CF}_{3} \mathrm{Br}$. Experimental data from several swarm experiments (for details, see the discussion in Ref. 2) are summarized. In the covered temperature range, the data are well described by a fit (full curve) which is based on the expression:

$$
k(T)=k_{0}+k_{\mathrm{A}} \exp \left[\frac{-E_{\mathrm{a}}}{k_{\mathrm{B}} T}\right],
$$

where the fitted parameters are $E_{\mathrm{a}}=67(3) \mathrm{meV}, k_{0}=1.3(2)$ $\times 10^{-10} \mathrm{~cm}^{3} \mathrm{~s}^{-1}$, and $k_{\mathrm{A}}=1.95(20) \times 10^{-7} \mathrm{~cm}^{3} \mathrm{~s}^{-1}$ (the number in parentheses represents the uncertainty in the final digits). Note that $k_{0} \ll k_{\mathrm{A}}$, and this is expected in general if the activation energy is substantial (i.e., $k_{\mathrm{B}} T \ll E_{\mathrm{a}}$ with $T$ near room temperature). The essential behavior shown in Fig. 1 was recovered in model R-matrix calculations (broken curve 


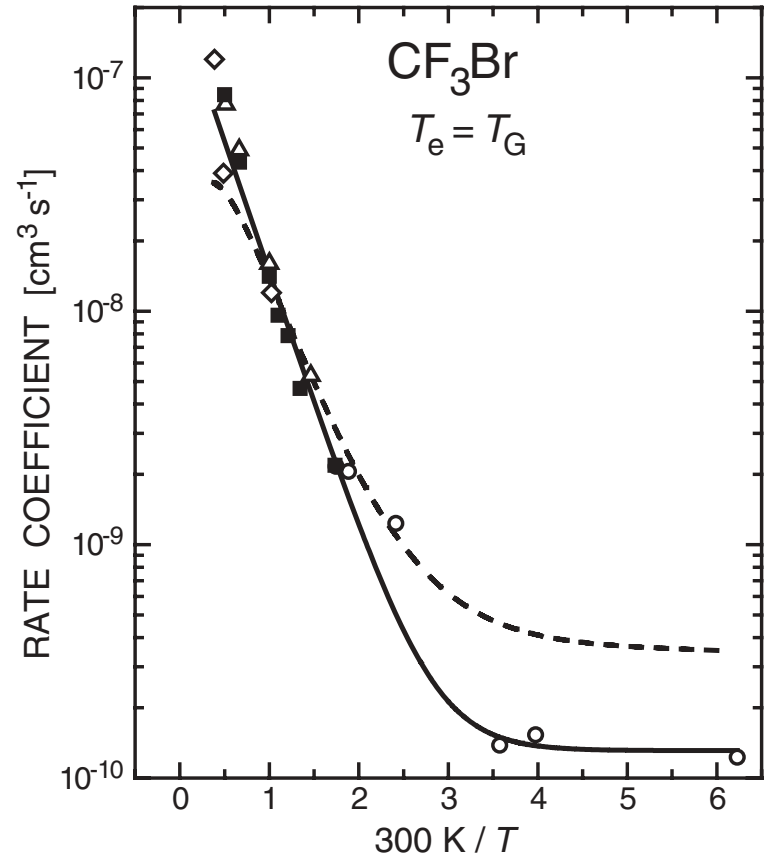

FIG. 1. Temperature dependence of the rate coefficients $k(T)$ for DEA to $\mathrm{CF}_{3} \mathrm{Br}$. (Symbols) Data from different swarm experiments (see Ref. 2 for references). (Full curve) Fit to the experimental data using the expression (3). (Broken curve) Results from R-matrix calculations. ${ }^{2}$

in Fig. 1) (Refs. 1 and 2) which predict deviations (i.e., saturation) from the exponential increase at high temperatures.

In the R-matrix calculations, the molecules were described as one-dimensional systems (i.e., quasidiatomic molecules) as depicted in Fig. 2 for the case $\mathrm{CF}_{3} \mathrm{Br}$. The neutral and the anion potential curves are denoted by $V(R)$ and $U(R)$, respectively. The most important quantities for the size of the thermal DEA rate coefficient are the separation $\Delta R$ $=R_{\mathrm{C}}-R_{\mathrm{e}}$ between the crossing point $R_{\mathrm{C}}$ [defined by $V\left(R_{\mathrm{C}}\right)$ $\left.=U\left(R_{\mathrm{C}}\right)\right]$ and the equilibrium distance $R_{\mathrm{e}}$ of the neutral potential and the height of the intermediate barrier $E_{\mathrm{C}}=V\left(R_{\mathrm{C}}\right)$ $-V\left(R_{\mathrm{e}}\right)$. In addition, the vertical attachment energy (VAE) [defined as the difference $U\left(R_{\mathrm{e}}\right)-V\left(R_{\mathrm{e}}\right)$ ], the autodetachment width of the anion system, and the vibrational frequency $\omega$ of the neutral molecule are relevant, especially when the barrier height $E_{C}$ is not substantially larger than the vibrational quantum $\hbar \omega$. Both endothermic and exothermic DEA processes with intermediate barrier (such as those represented by Fig. 2) have been treated in Ref. 1. In the endothermic case, Arrhenius-type behavior was observed and the extracted activation energies were found to be in close agreement with the reaction thresholds (note that for endothermic cases, $k_{0}=0$ ).

The question how the molecular parameters, especially the value of VAE, influence the size of the DEA cross sections has been investigated in detail by Burrow and coworkers. ${ }^{3,4}$ For several groups of related molecules (e.g., closed-shell chlorinated hydrocarbons), they investigated the decrease of the DEA peak cross section $\sigma_{\mathrm{P}}$ (VAE) for the first shape resonance above zero energy with rising vertical attachment energy and rationalized their observations with model calculations. ${ }^{3}$ More recently, Gallup et $a l .{ }^{4}$ analyzed absolute near-zero energy DEA yields of 18 chloroalkane molecules

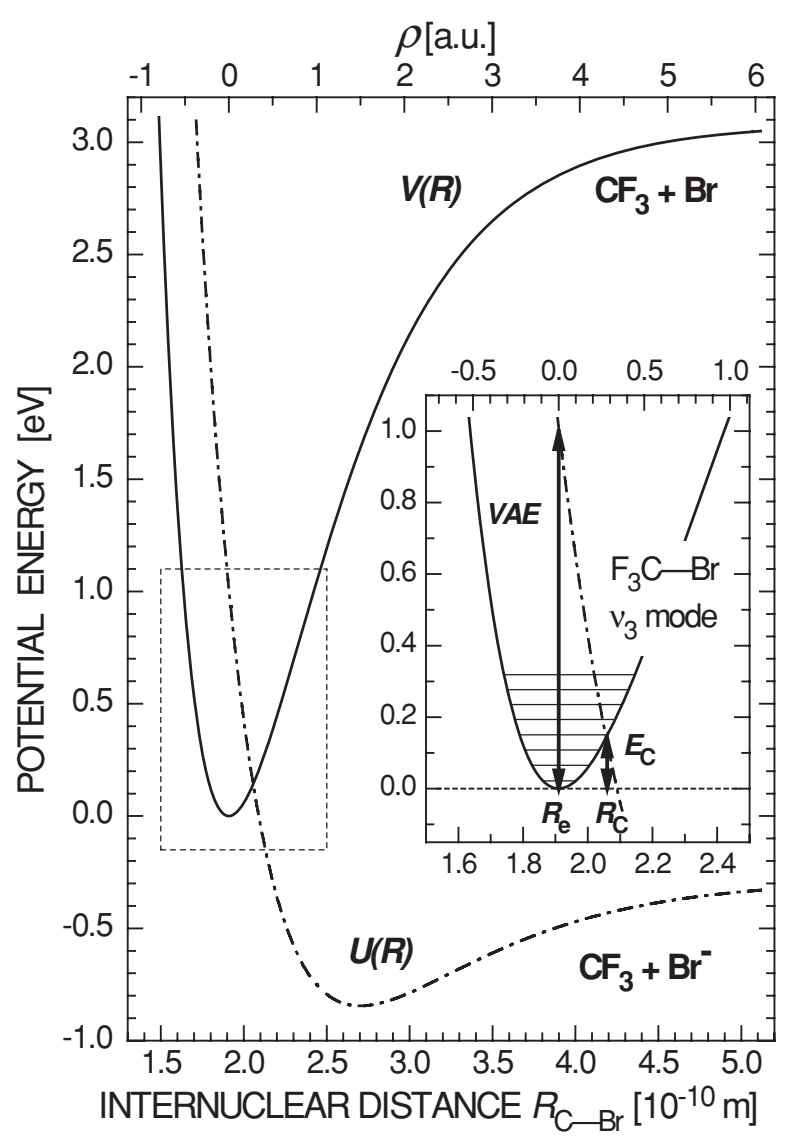

FIG. 2. Potential curves relevant for DEA to $\mathrm{CF}_{3} \mathrm{Br}$ (for details see Ref. 2). VAE: vertical attachment energy and $E_{\mathrm{C}}$ : classical barrier energy.

in terms of analytical model cross sections. The yields were obtained by Burrow et al. in electron beam experiments (gas temperature around $300 \mathrm{~K}$, energy widths around $0.1 \mathrm{eV}$ ). Using the fitted cross sections, they determined "integrated half zero peak cross sections" (which we denote as $I_{\text {Beam }}$ ) as well as thermal rate coefficients $k_{\text {Beam }}(T \approx 300 \mathrm{~K})$; the latter agreed quite well with those from the electron swarm data. For this series of molecules with VAE values up to about $2 \mathrm{eV}$, they found that both $I_{\text {Beam }}$ (Fig. 3 in Ref. 4) and $k_{\text {Beam }}$ (Fig. 6 in Ref. 4) exhibited an exponential dependence on VAE, i.e.,

$$
\begin{aligned}
& I_{\text {Beam }} \propto \exp \left(\frac{-\mathrm{VAE}}{V_{\mathrm{I}}}\right), \\
& k_{\text {Beam }} \propto \exp \left(\frac{-\mathrm{VAE}}{V_{\mathrm{K}}}\right) .
\end{aligned}
$$

From their Figs. 3 and 6, one obtains the values $V_{\mathrm{I}}$ $=192 \mathrm{meV}$ and $V_{\mathrm{K}}=198 \mathrm{meV}$, i.e., the slopes of the two graphs yield essentially consistent results. Gallup et al. related their observation (4) to the Arrhenius-type dependence $\exp \left[-E_{\mathrm{b}} /\left(k_{\mathrm{B}} T\right)\right]$ (with $E_{\mathrm{b}}$ denoted as "barrier or activation energy" ), and-using $T=300 \mathrm{~K}$-they found

$$
\frac{E_{\mathrm{b}}}{\mathrm{VAE}} \approx 0.135 \text {. }
$$

Gallup et al. also carried out simplified calculations of the quantity $I_{\text {Beam }}$ and $k_{\text {Beam }}$ by using model potential curves 


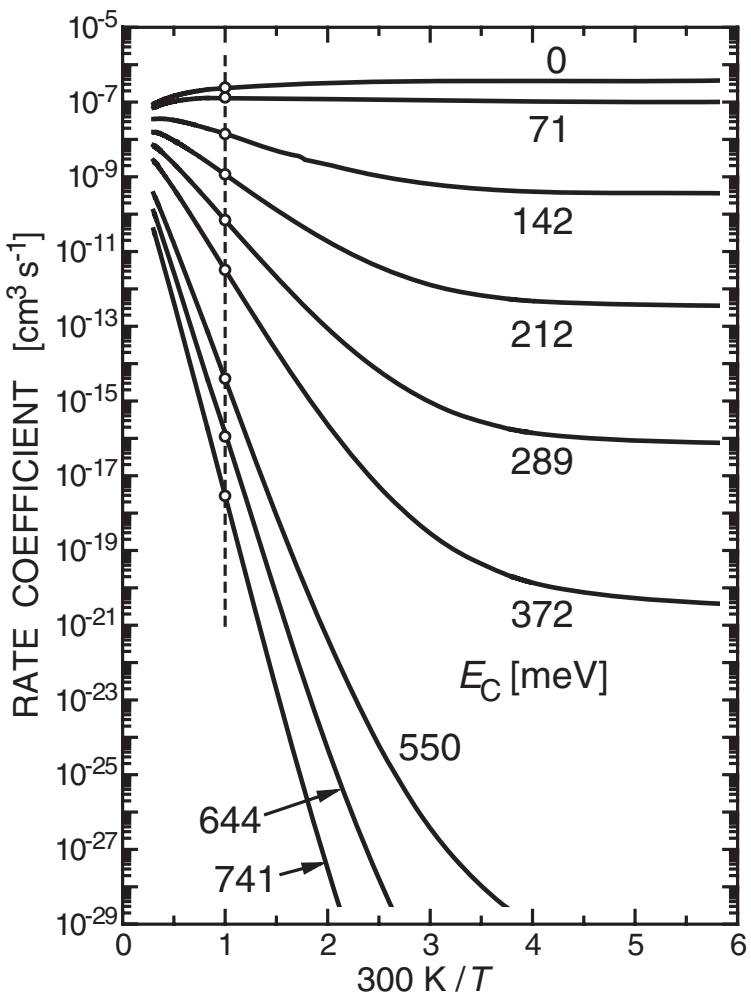

FIG. 3. Calculated DEA rate coefficients $k(T)$ for the nine exothermic cases listed in Table I. The vibrational energy quantum is fixed $(43.3 \mathrm{meV})$ while the classical barrier energy $E_{\mathrm{C}}$ varies from 0 to $741 \mathrm{meV}$. The open circles denote the respective rate coefficients at $T=300 \mathrm{~K}$ (see Table I).

with varying VAE and found satisfactory agreement with the experimental dependence on VAE.

More recently, an exponential relationship between the room-temperature DEA rate coefficient $k(T \approx 300 \mathrm{~K})$ for about a dozen halogenated hydrocarbon molecules and the associated experimental activation energy $E_{\mathrm{a}}$ was suggested by Kopyra et al. ${ }^{5,6}$ This relation may be written as

$$
k(T \approx 300 K)=k_{1} \exp \left(\frac{-E_{\mathrm{a}}}{E_{0}}\right) .
$$

The prefactor $k_{1}$ can be interpreted as the electron capture rate coefficient for strongly attaching molecules with (near-) zero activation energy (such as $\mathrm{CCl}_{4}$ ) at room temperature (typical values lying around $3 \times 10^{-7} \mathrm{~cm}^{3} \mathrm{~s}^{-1}$ ). It may also be quantified as the rate coefficient for s-wave electron capture at $T=300 \mathrm{~K}$ which takes values in the rather narrow range (2.83.7) $\times 10^{-7} \mathrm{~cm}^{3} \mathrm{~s}^{-1}$ when calculated for molecules with typical values of polarizabilities and electric dipole moments. ${ }^{7}$ In comparing the experimental data with Eq. (7), Kopyra et al. ${ }^{6}$ adopted the value $k_{1}=5 \times 10^{-7} \mathrm{~cm}^{3} \mathrm{~s}^{-1}$, i.e., the rate coefficient calculated for $T=300 \mathrm{~K}$ with the maximum reactive s-wave scattering cross section $\lambda^{2} /(4 \pi)(\lambda=$ de Broglie wavelength of the electron). In any case-even allowing for variations due to the individual molecular properties-the prefactor $k_{1}$ is expected to vary rather little as compared to the strong exponential dependence on activation energy. The slope parameter $E_{0}$ in Eq. (7) may-in the spirit of Eq. (1) — be simply set equal to $E_{0}=k_{\mathrm{B}} 300 \mathrm{~K}=25.85 \mathrm{meV}$, and this was in fact done by Kopyra et al. (Fig. 2 in Ref. 6). Otherwise, the value of $E_{0}$ can be determined from a fit to the experimental data using Eq. (7).

In this paper we shall try to theoretically justify the relation (7). As experimental database we use critically chosen rate coefficients at room temperature for a selection of closedshell halogenated hydrocarbon molecules which span a wide range of activation energies (up to about $0.7 \mathrm{eV}$ ) ${ }^{5,6,8-27} \mathrm{We}$ emphasize that for DEA systems with large activation energies rate coefficients at room temperature are very small; thus they are difficult to measure directly, and impurities in the molecular sample have to be assessed with great care.

For comparison with the experimental data we calculate rate coefficients with the semiempirical resonance R-matrix theory for quasidiatomic model systems akin to relevant molecular systems, covering a wide range of activation energies. Some results are taken from Ref. 1, several others (in particular for the special case of the $\mathrm{CH}_{2} \mathrm{Cl}_{2}$ molecule) are added in the present work. The theoretical results are found to support the exponential dependence of the thermal rate coefficients $(T \approx 300 \mathrm{~K})$ on activation energy. We also discuss the relation between the quantities $E_{\mathrm{a}}, E_{\mathrm{C}}$, and VAE. Limitations of the predictive power of these findings are mentioned.

\section{RESULTS AND DISCUSSION}

In Table I, we summarize important parameters and results of the model R-matrix calculations for exothermic DEA with intermediate barrier. The (fixed) neutral potential curve was modeled as that relevant for $\mathrm{CF}_{3} \mathrm{Br}$ along the $\mathrm{C}-\mathrm{Br}$ stretch mode $v_{3}(\hbar \omega=43.3 \mathrm{meV})$ (see Fig. 2). The shape of the anion curve was taken as that shown in Fig. 2; its asymptote for $R_{\mathrm{C}-\mathrm{Br}} \rightarrow \infty$ lies $0.283 \mathrm{eV}$ below the minimum of the neutral potential. To simulate cases with different values of the barrier energy $E_{\mathrm{C}}$ (and VAE), the anion curve $U(R)$ was simply shifted by various amounts $\rho_{\mathrm{s}}$-relative to the case $\rho_{\mathrm{s}}=0$ shown in Fig. 2 - to larger $\left(\rho_{\mathrm{s}}>0\right)$ or smaller

TABLE I. Parameters and results of the R-matrix calculations for exothermic DEA cases involving intermediate barriers with different classical barrier heights $E_{\mathrm{C}}$ and vertical attachment energies VAE, but fixed vibrational quantum $\hbar \omega=43.3 \mathrm{meV}$ (shift model). $\rho_{\mathrm{s}}$ denotes the shift of the anion potential energy curve (see text). $E_{\mathrm{a}}$ represents the activation energy deduced from the exponential slope (around $T=300 \mathrm{~K}$ ) of the calculated rate coefficients $k(T)$

\begin{tabular}{ccccc}
\hline \hline $\begin{array}{l}\rho_{\mathrm{s}} \\
(\text { a.u. })^{\mathrm{a}}\end{array}$ & $\begin{array}{c}\text { VAE } \\
(\mathrm{eV})\end{array}$ & $\begin{array}{c}E_{\mathrm{C}} \\
(\mathrm{meV})\end{array}$ & $\begin{array}{c}E_{\mathrm{a}} \\
(\mathrm{meV})\end{array}$ & $\begin{array}{c}k(T=300 \mathrm{~K}) \\
\left(\mathrm{cm}^{3} \mathrm{~s}^{-1}\right)\end{array}$ \\
\hline-0.34 & 0 & 0 & $(-15)^{\mathrm{b}}$ & $2.44 \times 10^{-7}$ \\
-0.12 & 0.59 & 71 & $(-3)^{\mathrm{b}}$ & $1.33 \times 10^{-7}$ \\
0.0 & 1.01 & 142 & 52 & $1.39 \times 10^{-8}$ \\
0.1 & 1.45 & 212 & 109 & $1.15 \times 10^{-9}$ \\
0.2 & 1.96 & 289 & 177 & $6.92 \times 10^{-11}$ \\
0.3 & 2.58 & 372 & 252 & $3.22 \times 10^{-12}$ \\
0.5 & 4.15 & 550 & 419 & $3.95 \times 10^{-15}$ \\
0.6 & 5.15 & 644 & 511 & $1.12 \times 10^{-16}$ \\
0.7 & 6.33 & 741 & 606 & $2.87 \times 10^{-18}$ \\
\hline \hline
\end{tabular}

${ }^{a} 1$ a.u. $=0.5291772 \times 10^{-10} \mathrm{~m}$ (see also $\rho$-scale, i.e., upper abscissa, in Fig. 2).

${ }^{\mathrm{b}}$ No extended range of exponential behavior; slope evaluated at $T=300 \mathrm{~K}$. 
internuclear distances, as listed in Table I ("anion potential shift model," in the following abbreviated as "shift model"). The surface amplitude (the square of which being proportional to the autodetachment width function) was chosen as that found adequate in describing DEA to $\mathrm{CF}_{3} \mathrm{Br} ;{ }^{2}$ it was kept fixed in the calculations. This means that the nonlocal autodetachment width $\Gamma(E, \rho)$ (Ref. 28) as a function of the electron energy $E$ and the relative internuclear distance $\rho$ was the same in all calculations. However, because of the variation of $U(\rho)$ the effective width was affected as well. To understand this, it is instructive to consider the width in the local approximation whereby the argument $E$ of the function $\Gamma(E, \rho)$ is replaced by the adiabatic energy $U(\rho)-V(\rho) .{ }^{28}$ This quantity indicates the electron energy which is most important for a given $\rho$. Therefore, when $U(\rho)$ is varied, the effective width is affected too.

In Fig. 3, we show the calculated dependences $k(T)$ for nine cases with classical barrier heights $E_{\mathrm{C}}$ between 0 and $741 \mathrm{meV}$. As abscissa, we use the normalized inverse temperature $300 \mathrm{~K} / T$ over the range $0.25-6$. The open circles in Fig. 3 denote the rate coefficients for $T=300 \mathrm{~K}\left(\hbar \omega /\left(k_{\mathrm{B}} T\right)\right.$ $=1.675)$. For substantial or large activation energies $\left(E_{\mathrm{C}} / \hbar \omega\right.$ $>3$ ), the rate coefficients at $T=300 \mathrm{~K}$ are located in the range of temperatures within which Eq. (1) [or the modified expression Eq. (3)] is a valid approximation for the temperature dependence of $k(T)$. For low barrier heights (i.e., $E_{\mathrm{C}} / \hbar \omega$ $<2$ ), the rate coefficients $k(T)$ are nearly independent of temperature for $T>300 \mathrm{~K}$ and decrease weakly to higher temperatures. In this range of $E_{\mathrm{C}} / \hbar \omega$ values, the Franck-Condon factor for the electron capture process is high for the lowest vibrational level at low electron energies. Correspondingly, the activation energy is close to zero.

Activation energies $E_{\mathrm{a}}$ were determined from the slope of the $k(T)$ curves in Fig. 3 around $T=300 \mathrm{~K}$ and are listed in Table I. Equation (1) is a good approximation of $k(T)$ at temperatures around $300 \mathrm{~K}$ as long as the barrier $E_{\mathrm{C}}$ is sufficiently high compared to the thermal energy at $300 \mathrm{~K}(25.85 \mathrm{meV})$. For these cases (i.e., for $E_{\mathrm{C}}>71 \mathrm{meV}$ in Table I) the values of $E_{\mathrm{a}}$ are found to be always distinctly smaller than the barrier energy $E_{\mathrm{C}}$ (by amounts between 90 and $135 \mathrm{meV}$, i.e., much larger than the vibrational zero-point energy of the neutral molecule) due to quantum effects including barrier penetration by tunneling. Correspondingly, the ratios $E_{\mathrm{a}} / E_{\mathrm{C}}$-which rise toward larger $E_{\mathrm{C}}$ - stay substantially below unity.

A plot of the theoretically determined values $k(T$ $=300 \mathrm{~K}$ ) versus $E_{\mathrm{a}}$, shown in Fig. 4, exhibits an exponential dependence and supports Eq. (7) with fitted parameters (uncertainties below $1 \%) k_{1}^{\mathrm{Th}}=1.04 \times 10^{-7} \mathrm{~cm}^{3} \mathrm{~s}^{-1}$ and $E_{0, \mathrm{a}}^{\mathrm{Th}}$ $=24.7 \mathrm{meV}$. Likewise, a plot of the theoretically determined $k(T=300 \mathrm{~K})$ values versus the barrier energy $E_{\mathrm{C}}$ closely follows an exponential dependence with a slope parameter $E_{0, \mathrm{C}}^{\mathrm{Th}}=27.1 \mathrm{meV}$. We note that the two slope parameters $E_{0, \mathrm{a}}^{\mathrm{Th}}$ and $E_{0, \mathrm{C}}^{\mathrm{Th}}$ differ only little from the thermal energy $k_{\mathrm{B}} T$ $=25.85 \mathrm{meV}$ at $T=300 \mathrm{~K}$.

A plot of $k(T=300 \mathrm{~K})$ versus VAE also shows an overall exponential behavior (slope parameter $E_{0, \mathrm{VAE}}^{\mathrm{Th}}=218 \mathrm{meV}$ ), but some of the calculated rate coefficients differ substantially from the fit curve (by a factor of up to 20). These observations are in qualitative agreement with those of Gallup et al. ${ }^{4}$
The theoretical predictions for the relation $k\left(E_{\mathrm{a}}\right)$ documented in Fig. 4 confirm the behavior which was indicated by the variation of experimental rate coefficients $k(T$ $\approx 300 \mathrm{~K})$ with experimentally determined activation energies. ${ }^{5,6}$ In Fig. 4, we have included rate coefficients for 14 halogenated alkane molecules (represented by open stars) which were obtained close to room temperature (293-300 K) with various electron swarm methods. For the cases with high activation energies, the values $k(T \approx 300 \mathrm{~K})$ were determined by extrapolation of data taken at higher temperatures (shown with error bars in Fig. 4). The associated experimental activation energies $E_{\mathrm{a}}$ are either original values or were obtained by reevaluation of data in the quoted literature. These critically chosen results ${ }^{5,6-27}$ are listed and commented in Table II.

We note that for two molecules included in Table II and Fig. 4 the DEA reaction at $T=300 \mathrm{~K}$ is essentially thermoneutral $\left(\mathrm{CH}_{3} \mathrm{Cl}\right)$ (Refs. 11 and 25) or even endothermic by $0.17(4) \mathrm{eV}\left(\mathrm{CF}_{3} \mathrm{Cl}\right)$ (Ref. 21). Since the activation energies are substantially higher than the endothermicities for these systems, the temperature dependences of the DEA rate coefficients are dominated by the respective intermediate barrier, and this justifies the inclusion of these molecules into the

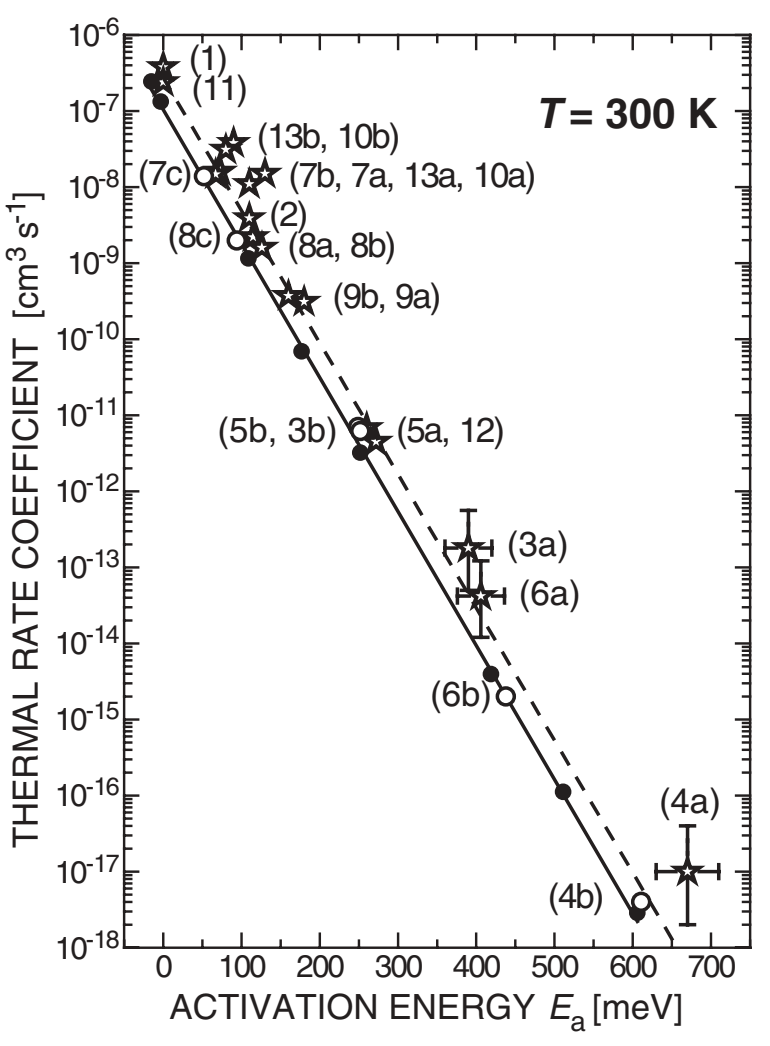

FIG. 4. Variation of the thermal $(T=300 \mathrm{~K})$ DEA rate coefficients with the activation energy $E_{\mathrm{a}}$. (Full circles) R-matrix calculation with parameters listed in Table I (shift model). (Open circles) R-matrix calculations for specific molecules (see Table II and text). (Full line): Fit to the results of the R-matrix calculations (shift model). (Open stars) Selected experimental data, labeled by numbers as follows (for details see Table II): (1) $\mathrm{CCl}_{4}$; (2) $\mathrm{CHCl}_{3}$; (3) $\mathrm{CH}_{2} \mathrm{Cl}_{2}$; (4) $\mathrm{CH}_{3} \mathrm{Cl}$; (5) $\mathrm{CH}_{3} \mathrm{Br}$; (6) $\mathrm{CF}_{3} \mathrm{Cl}$; (7) $\mathrm{CF}_{3} \mathrm{Br}$; (8) $\mathrm{CF}_{2} \mathrm{Cl}_{2}$; (9) $\mathrm{CHCl}_{2} \mathrm{CH}_{2} \mathrm{Cl}$; (10) $\mathrm{CH}_{3} \mathrm{CCl}_{3}$; (11) $\mathrm{CF}_{3} \mathrm{CCl}_{3}$; (12) $\mathrm{CH}_{2} \mathrm{ClCH}_{2} \mathrm{Cl}$; (13) $\mathrm{CF}_{2} \mathrm{ClCFCl}_{2}$; (14) $\mathrm{CH}_{3} \mathrm{CHClCH}_{2} \mathrm{CH}_{3}$. (Broken line) Fit to the experimental data. 
TABLE II. Thermal electron attachment rate coefficients $k(T \approx 300 \mathrm{~K})$ and activation energies $E_{\mathrm{a}}$ for selected molecules. Experimental and theoretical values are displayed in Fig. 4 according to the listed labels. EDS: electron density sampling; ESR: electron spin resonance; FALP: flowing afterglow Langmuir probe; MCD: microwave conductivity detector.

\begin{tabular}{|c|c|c|c|c|}
\hline Molecule (label) & Label Fig. 4 & $\begin{array}{c}k(T \approx 300 \mathrm{~K}) \\
\left(\mathrm{cm}^{3} \mathrm{~s}^{-1}\right)\end{array}$ & $\begin{array}{l}E_{\mathrm{a}} \\
(\mathrm{eV})\end{array}$ & Method, reference \\
\hline $\mathrm{CCl}_{4}(1)$ & (1) & $3.79(19) \times 10^{-7}$ & $\approx 0^{\mathrm{a}}$ & Cavallieri EDS, Ref. 9 \\
\hline $\mathrm{CHCl}_{3}(2)$ & (2) & $3.9(2) \times 10^{-9}$ & $0.11(1)$ & Drift tube (carrier gas $\mathrm{CO}_{2}$ ), Ref. 11 \\
\hline \multirow[t]{3}{*}{$\mathrm{CH}_{2} \mathrm{Cl}_{2}(3)$} & & $6_{-4}^{+11} \times 10^{-12 b, c}$ & $0.25(3)^{\mathrm{c}}$ & Flowing afterglow-ESR, Ref. 12 \\
\hline & (3a) & $1.8_{-1.3}^{+3.8} \times 10^{-13 \mathrm{~b}, \mathrm{~d}}$ & $0.39(3)^{\mathrm{d}}$ & $T$-variable FALP, Ref. 8 \\
\hline & $(3 b)$ & $6.2 \times 10^{-12}$ & 0.252 & R-matrix calculation, present \\
\hline \multirow[t]{4}{*}{$\mathrm{CH}_{3} \mathrm{Cl}(4)$} & & $<1.9 \times 10^{-15}$ & & MCD, Ref. 13 \\
\hline & & & $0.54(2)$ & Electron capture detector, Ref. 14 \\
\hline & (4a) & $1.0_{-0.8}^{+3} \times 10^{-17 \mathrm{~b}, \mathrm{~d}}$ & $0.67(4)^{d}$ & $T$-variable FALP, Refs. 8 and 25 \\
\hline & (4b) & $4.0 \times 10^{-18}$ & 0.611 & R-matrix calculation, Ref. 15 \\
\hline \multirow[t]{2}{*}{$\mathrm{CH}_{3} \mathrm{Br}(5)$} & (5a) & $6.78(27) \times 10^{-12}$ & $0.260(15)$ & Cavallieri EDS, Ref. 16 \\
\hline & $(5 b)$ & $7 \times 10^{-12}$ & $0.249^{\mathrm{e}}$ & R-matrix calculation, Ref. 15 \\
\hline \multirow[t]{5}{*}{$\mathrm{CF}_{3} \mathrm{Cl}(6)$} & & $2 \times 10^{-13}$ & & Drift tube, Ref. 18 \\
\hline & & $5.2 \times 10^{-14}$ & & MCD, Ref. 27 \\
\hline & & $3.0_{-2.5}^{+10} \times 10^{-14 \mathrm{~b}, \mathrm{c}}$ & $0.43(4)^{\mathrm{c}, \mathrm{f}}$ & Flowing afterglow-ESR, Ref. 12 \\
\hline & (6a) & $4.2_{-3}^{+8} \times 10^{-14 \mathrm{~b}, \mathrm{~d}}$ & $0.406(30)^{\mathrm{d}}$ & $T$-variable FALP, Ref. 8 \\
\hline & (6b) & $2 \times 10^{-15}$ & 0.438 & R-matrix calculation, Ref. 19 \\
\hline \multirow[t]{5}{*}{$\mathrm{CF}_{3} \mathrm{Br}(7)$} & & $1.6(2) \times 10^{-8}$ & $0.080(16)$ & $T$-variable FALP, Ref. 20 \\
\hline & (7a) & $1.6(2) \times 10^{-8}$ & $0.073(8)^{\mathrm{c}}$ & $T$-variable FALP, Ref. 20 \\
\hline & & $1.2 \times 10^{-8}$ & $0.075(8)^{\mathrm{c}}$ & Flowing afterglow-ESR, Ref. 12 \\
\hline & (7b) & $1.47(21) \times 10^{-8 g}$ & $0.067(3)^{\mathrm{g}}$ & Several methods, present fit \\
\hline & (7c) & $1.39 \times 10^{-8}$ & 0.052 & R-matrix calculation, present \\
\hline \multirow[t]{4}{*}{$\mathrm{CF}_{2} \mathrm{Cl}_{2}(8)$} & & $(0.7-5.9) \times 10^{-9}$ & $0.11-0.195$ & Several methods, data in Table I of Ref. 22 \\
\hline & (8a) & $2.2(8) \times 10^{-9 g}$ & $0.115(6)^{\mathrm{g}}$ & Several methods, fit in Ref. 21 \\
\hline & (8b) & $1.6(4) \times 10^{-9}$ & $0.126(10)$ & $T$-variable FALP, Ref. 8 \\
\hline & (8c) & $1.98 \times 10^{-9}$ & 0.094 & R-matrix calculation, present \\
\hline \multirow[t]{3}{*}{$\mathrm{CHCl}_{2} \mathrm{CH}_{2} \mathrm{Cl}(9)$} & & $3.1(6) \times 10^{-10}$ & 0.200 & $T$-variable FALP, Refs. 23 and 26 \\
\hline & (9a) & $3.1(6) \times 10^{-10}$ & $0.18(5)^{\mathrm{c}}$ & $T$-variable FALP, Ref. 23 \\
\hline & $(9 b)$ & $3.7(4) \times 10^{-10}$ & $0.16(2)$ & Drift tube (carrier gas $\mathrm{CO}_{2}$ ), Ref. 5 \\
\hline \multirow[t]{3}{*}{$\mathrm{CH}_{3} \mathrm{CCl}_{3}(10)$} & & $1.5(3) \times 10^{-8}$ & 0.130 & $T$-variable FALP, Refs. 23 and 26 \\
\hline & $(10 \mathrm{a})$ & $1.5(3) \times 10^{-8}$ & $0.13(3)^{\mathrm{c}}$ & $T$-variable FALP, Ref. 23 \\
\hline & $(10 b)$ & $3.8(7) \times 10^{-8}$ & $0.09(2)$ & Drift tube (carrier gas $\mathrm{CO}_{2}$ ), Ref. 5 \\
\hline \multirow[t]{2}{*}{$\mathrm{CF}_{3} \mathrm{CCl}_{3}(11)$} & (11) & $2.4(5) \times 10^{-7}$ & $\approx 0$ & $T$-variable FALP, Refs. 23 and 26 \\
\hline & & $2.25(11) \times 10^{-7}$ & & Kondo and Crompton, cited in Ref. 24 \\
\hline $\mathrm{CH}_{2} \mathrm{ClCH}_{2} \mathrm{Cl}(12)$ & $(12)$ & $4.5(8) \times 10^{-12}$ & $0.272(14)$ & Drift tube (carrier gas $\mathrm{CO}_{2}$ ), present \\
\hline \multirow{3}{*}{$\mathrm{CF}_{2} \mathrm{ClCFCl}_{2}$} & & $1.1(2) \times 10^{-8}$ & 0.110 & $T$-variable FALP, Refs. 23 and 26 \\
\hline & (13a) & $1.1(2) \times 10^{-8}$ & $0.11(3)^{\mathrm{c}}$ & $T$-variable FALP, Ref. 23 \\
\hline & $(13 b)$ & $3.1(1) \times 10^{-8}$ & $0.08(1)$ & Drift tube (carrier gas $\mathrm{CO}_{2}$ ), Ref. 6 \\
\hline $\mathrm{CH}_{3} \mathrm{CHClCH}_{2} \mathrm{CH}_{3}$ (14) & & $2 \times 10^{-15 h}$ & $0.55(2)$ & Drift tube (carrier gas $\mathrm{CO}_{2}$ ), Ref. 5 \\
\hline
\end{tabular}

${ }^{a}$ Estimate from data in Ref. 10, see also Ref. 26.

${ }^{\mathrm{b}}$ Extrapolated from data at high temperatures.

${ }^{\mathrm{c}}$ Present evaluation of original data.

${ }^{\mathrm{d}}$ Due to a more elaborate analysis, the error of $E_{\mathrm{a}}$ was reduced to about $60 \%$ of the published value and used to fix the error bar for the extrapolated $k(T=300 \mathrm{~K})$ value.

${ }^{\mathrm{e}}$ Cited in Braun et al (Ref. 17).

${ }^{\mathrm{f}}$ Upper limit of $4 \times 10^{-13} \mathrm{~cm}^{3} \mathrm{~s}^{-1}$ at $293 \mathrm{~K}$ (Ref. 12) not included in $E_{\mathrm{a}}$ fit.

${ }^{\mathrm{g}}$ Fitted average from several data, using Eq. (3).

${ }^{\mathrm{h}}$ Upper limit, extrapolated from data at temperatures above $340 \mathrm{~K}$.

discussion of "exothermic DEA systems with intermediate barrier."

For $\mathrm{CF}_{3} \mathrm{Cl}$ the rate coefficient $k(T=298 \mathrm{~K})$ $=5.2 \times 10^{-14} \mathrm{~cm}^{3} \mathrm{~s}^{-1}$, reported by Fessenden and Bansal, ${ }^{27}$ supports the extrapolated value of Miller et al. ${ }^{8}$ and the result which we obtain by extrapolation of the data in Ref. 12. We note that in our $E_{\text {a }}$ fit of the data from Ref. 12 we did not include the rate coefficient quoted in Ref. 12 for $293 \mathrm{~K}\left(4 \times 10^{-13} \mathrm{~cm}^{3} \mathrm{~s}^{-1}\right)$ and stated to be an upper limit. Specific R-matrix calculations have been reported earlier for DEA to $\mathrm{CH}_{3} \mathrm{Cl}$ (Refs. 15 and 29 and 30), $\mathrm{CH}_{3} \mathrm{Br}$ (Refs. 15 and 17), and $\mathrm{CF}_{3} \mathrm{Cl}$ (Ref. 19). They yielded activation energies of $0.611 \mathrm{eV},{ }^{15} 0.249 \mathrm{eV},{ }^{15,17}$ and $0.438 \mathrm{eV},{ }^{19}$ respectively, in satisfactory agreement with the experimental results $0.67(4) \mathrm{eV},{ }^{8,25} 0.260(15) \mathrm{eV},{ }^{16}$ and 0.406(30) eV (Ref. 8)/0.43(4) eV (Ref. 12) (see Table II). For $\mathrm{CH}_{3} \mathrm{Cl}$, we determined an independent estimate $E_{\mathrm{a}}$ $=0.73(4) \mathrm{eV}$ from the temperature-dependence of the zeroenergy peak in DEA beam experiments of Pearl et al..$^{30}$ and a theoretical value $E_{\mathrm{a}}=0.66 \mathrm{eV}$ from an earlier R-matrix 
calculation (model A in Ref. 30); these results are compatible with the flowing afterglow Langmuir probe (FALP) value of Miller et al. ${ }^{8,25}$

In the case of $\mathrm{CH}_{2} \mathrm{Cl}_{2}$, two data pairs $\left(k, E_{\mathrm{a}}\right)$ exist, based on the data of Burns et al. ${ }^{12}$ and Miller et al. ${ }^{8}$ (see Table II) which differ significantly from each other, but the pairs are both consistent with the general relation between $k$ and $E_{\mathrm{a}}$. This molecule is characterized by a large redshift of the peak in the DEA cross section at $0.43 \mathrm{eV}$ relative to the VAE value of $1.01 \mathrm{eV}$ (Ref. 3) and exhibits an astoundingly low peak cross section for that band as compared to those of other molecules with similar VAE. ${ }^{3}$ In order to shed some theoretical light on these aspects, we carried out new R-matrix calculations for the DEA cross section involving $\mathrm{CH}_{2} \mathrm{Cl}_{2}$ (Ref. 31). We found an activation energy of $0.252 \mathrm{eV}$, substantially below the recent FALP value of Miller et al. ${ }^{8}$ The calculated room temperature rate coefficient amounts to $6.2 \times 10^{-12} \mathrm{~cm}^{3} \mathrm{~s}^{-1}$, much higher than the (extrapolated) experimental value of $1.8 \times 10^{-13} \mathrm{~cm}^{3} \mathrm{~s}^{-1}$ (Ref. 8). On the other hand, the Boston College measurements ${ }^{12}$ yield an activation energy $[0.25(3) \mathrm{eV}]$ and rate coefficient $\left(6 \times 10^{-12} \mathrm{~cm}^{3} \mathrm{~s}^{-1}\right.$, extrapolated to $300 \mathrm{~K}$ ) in good agreement with the present calculations. In addition, several earlier measurements (e.g., Ref. 27, see also Ref. 32) consistently give a value of the rate coefficient at room temperature, $k \approx 4.7 \times 10^{-12} \mathrm{~cm}^{3} \mathrm{~s}^{-1}$, which is in satisfactory agreement with our calculations.

For the molecule $\mathrm{CH}_{2} \mathrm{ClCH}_{2} \mathrm{Cl}$, new measurements were carried out with the drift-tube setup in Siedlce which involves a pulsed Townsend technique described in Refs. 5 and 6. Carbon dioxide is used as a buffer gas (pressure of around $530 \mathrm{mbar}$ ) which quickly thermalizes the electron swarm. $\mathrm{CH}_{2} \mathrm{ClCH}_{2} \mathrm{Cl}$ (i.e., $1,2-\mathrm{C}_{2} \mathrm{H}_{4} \mathrm{Cl}_{2}$ ) was provided by Sigma-Aldrich (stated purity 99.8\%). Special care was taken to purify the gas inlet and the drift tube. DEA rate coefficients were measured at nine temperatures, ranging from 298 to $378 \mathrm{~K}$. The data are presented as an Arrhenius-plot in Fig. 5. The slope of the fit curve yields an activation energy of $0.272(14) \mathrm{eV}$.

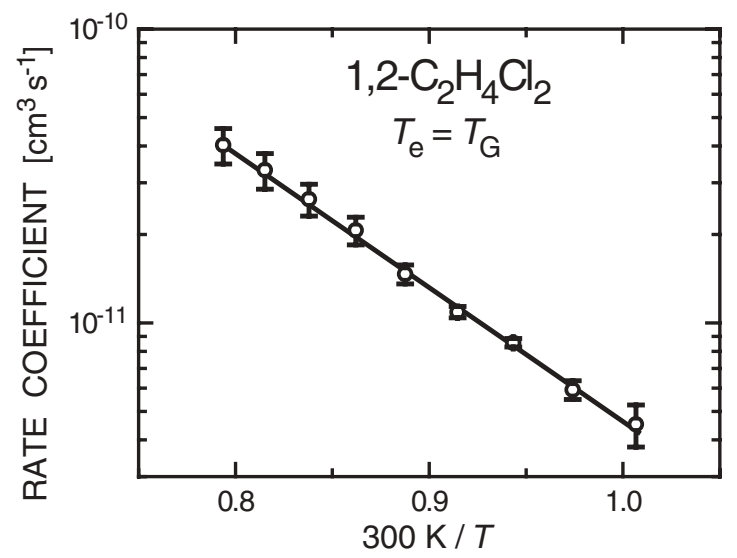

FIG. 5. Arrhenius-plot for the DEA rate coefficients of the molecule $\mathrm{CH}_{2} \mathrm{ClCH}_{2} \mathrm{Cl}\left(1,2-\mathrm{C}_{2} \mathrm{H}_{4} \mathrm{Cl}_{2}\right)$, measured with the Siedlce drift-tube apparatus over the temperature range $298-378 \mathrm{~K}$ (open circles). The fit curve yields the activation energy $0.272(14) \mathrm{eV}$.
The experimental data in Fig. 4 and Table II are in semiquantitative agreement with the calculated results. We conclude that at least for the considered molecular systems, an exponential relation between the thermal DEA rate coefficients and the associated activation energies exists, as suggested by Kopyra et $a l .{ }^{5,6}$ A fit to the experimental data (weighted by the respective error bars of $E_{\mathrm{a}}$ ) with Eq. (7) yields $k_{1}^{\operatorname{Exp}}=$ $2.72(25) \times 10^{-7} \mathrm{~cm}^{3} \mathrm{~s}^{-1}$ and $E_{0}^{\operatorname{Exp}}=24.9(7) \mathrm{meV}$. It can thus be stated that the slope parameter $E_{0}=k_{\mathrm{B}} T=25.85 \mathrm{meV}(T$ $=300 \mathrm{~K}$ ) represents a reasonable approximation (within 5\%) for describing the dependence of the thermal rate coefficients $k(T=300 \mathrm{~K})$ on the activation energy for both the calculated and the experimental data.

The prefactor $k_{1}^{\mathrm{Th}}$ obtained from the calculations is about 2.6 times smaller than that determined from the fit to the experimental data. We judge that this difference has mainly two origins: (i) all the calculations have been carried out with a special autodetachment width function, as relevant for $\mathrm{CF}_{3} \mathrm{Br}$. This width function yields thermal rate coefficients for the cases with near-zero activation energy (see Fig. 3) which are significantly below the capture rate coefficient for this case $\left[k(300 \mathrm{~K})=2.95 \times 10^{-7} \mathrm{~cm}^{3} \mathrm{~s}^{-1}\right.$, calculated with formula from Ref. 7, using the dipole moment and polarizability of $\mathrm{CF}_{3} \mathrm{Br}$ quoted in Ref. 2]. (ii) The calculations use a simple one-dimensional model. Coupling of the dissociative mode with other vibrational modes of lower frequency may lower the activation energy and/or raise the rate coefficient.

How general are the findings presented in Fig. 4 ? It is clear that the model calculations incorporate assumptions on the molecular parameters and on the surface amplitude which will differ in detail from those appropriate for the real molecular systems. However, the agreement of the rate coefficients, calculated for several specific molecules using ab initio input for the molecular parameters (open circles in Fig. 4), with the trend predicted by the model calculations supports the idea that the exponential dependence of $k(T \approx 300 \mathrm{~K})$ on the activation energy reflects a general phenomenon associated with Franck-Condon factors for getting from the initial neutral vibrational state to the dissociating final state in a direct DEA process.

One can envision that DEA systems which involve the formation of long-lived anion complexes may show different behavior because in these cases the temperature dependence of the rate coefficients will also depend on the temperature dependent autodetachment time of the anion complex, on intramolecular vibrational redistribution and on pressuredependent collisional removal of excess energy. DEA reactions have in fact been reported which do not display the Arrhenius behavior indicated in Fig. 4. Notable exceptions have been found for sulfur compounds. The attachment rate coefficient for $\mathrm{SF}_{5} \mathrm{Cl}$ (yielding mainly the product $\mathrm{SF}_{5}{ }^{-}$) has been measured to be temperature independent (300-550 K, within experimental uncertainty) at $5 \times 10^{-8} \mathrm{~cm}^{3} \mathrm{~s}^{-1}$ (Ref. 33) [we note that Mayhew et al. ${ }^{34}$ measured a lower rate coefficient of $2.0(3) \times 10^{-8} \mathrm{~cm}^{3} \mathrm{~s}^{-1}$ in an atmospheric pressure of $\mathrm{CO}_{2}$ buffer gas at $300 \mathrm{~K}$ ]. DEA for several other $\mathrm{SF}_{5}$-containing compounds $\left(\mathrm{SF}_{5} \mathrm{C}_{6} \mathrm{H}_{5}, \mathrm{SF}_{5} \mathrm{C}_{2} \mathrm{H}_{3}, \mathrm{~S}_{2} \mathrm{~F}_{10}\right.$, and $\mathrm{SF}_{5} \mathrm{Br}$ ) may have very small rate coefficients accompanied 
by small $E_{\mathrm{a}}$ values. ${ }^{35}$ Data for sulfur oxyhalides have shown molecules which fit to the present picture $\left(\mathrm{SO}_{2} \mathrm{FCl}, \mathrm{SOCl}_{2}\right)$ and those which do not $\left(\mathrm{SO}_{2} \mathrm{Cl}_{2}, \mathrm{SO}_{2} \mathrm{~F}_{2}, \mathrm{SOF}_{2}\right){ }^{36}$

Another rather special example for non-Arrhenius behavior is offered by the chlorine molecule. For symmetry reasons, s-wave electron attachment is forbidden in the low-energy region which is dominated by the $\mathrm{Cl}_{2}{ }^{-}\left({ }^{2} \Sigma_{\mathrm{u}}{ }^{+}\right)$ resonance. ${ }^{37}$ Therefore, attachment proceeds via p-wave attachment which-in combination with the relevant FranckCondon factors for the neutral to anion transitions-yields a DEA rate coefficient $k(T)$ which rises with increasing temperature in a non-Arrhenius-type fashion over the range 200-1100 K (Ref. 38).

\section{CONCLUSIONS}

Calculations of temperature-dependent rate coefficients $k(T)$ for exothermic DEA processes involving a barrier on the path toward dissociation have been carried out with the aim to theoretically justify experimental observations on an exponential relation between the value of thermal $(T \approx 300 \mathrm{~K})$ DEA rate coefficients and the associated Arrhenius activation energy $E_{\mathrm{a}}$. The results of both model R-matrix calculations involving a simple anion potential shift model (activation energies between 0 and $0.61 \mathrm{eV}$ ) and of R-matrix calculations for specific molecules (including $\mathrm{CF}_{3} \mathrm{Br}, \mathrm{CF}_{2} \mathrm{Cl}_{2}$, $\mathrm{CH}_{3} \mathrm{Br}, \mathrm{CH}_{2} \mathrm{Cl}_{2}, \mathrm{CF}_{3} \mathrm{Cl}, \mathrm{CH}_{3} \mathrm{Cl}$ ) closely follow the exponential relation $k(T=300 \mathrm{~K}) \sim \exp \left(-E_{\mathrm{a}} / E_{0}\right)$ with a slope parameter of $E_{0}=24.7 \mathrm{meV}$ which is close to the thermal energy $(25.85 \mathrm{meV}$ at $300 \mathrm{~K})$ and in satisfactory agreement with the slope parameter [24.9(7) meV] of an exponential fit to critically assessed experimental data pairs $\left[k(T=300 \mathrm{~K}), E_{\mathrm{a}}\right]$ for 14 closed-shell molecules (halogenated alkanes, mainly methane and ethane derivatives). New reliable measurements of such data pairs, especially for molecules with high activation energies, are desirable to further test the relation between the size of the thermal DEA rate coefficient and the associated $E_{\mathrm{a}}$ value. Moreover, a better understanding of those cases which deviate from the exponential relation between $k$ and $E_{\mathrm{a}}$ is needed.

\section{ACKNOWLEDGMENTS}

This work has been stimulated by cooperations within the ESF network EIPAM (Electron-Induced Processing at the Molecular level). We acknowledge support by the Deutsche Forschungsgemeinschaft (HO 427/29). I.I.F. was supported by the US National Science Foundation Grant No. PHY-0652866 and by a Marie Curie International Incoming Fellowship (FP7-PEOPLE-2009-IIF - 252714). J. K. was supported by the Polish Ministry of Science and Higher Education. T.M.M. thanks the Air Force Office of Scientific Research for its support. We gratefully acknowledge
P. D. Burrow for comments on the manuscript and for providing detailed information on the work in Ref. 4.

${ }^{1}$ I. I. Fabrikant and H. Hotop, J. Chem. Phys. 128, 124308 (2008).

${ }^{2}$ S. Marienfeld, T. Sunagawa, I. I. Fabrikant, M. Braun, M.-W. Ruf, and H. Hotop, J. Chem. Phys. 124, 154316 (2006).

${ }^{3}$ K. Aflatooni and P. D. Burrow, J. Chem. Phys. 113, 1455 (2000).

${ }^{4}$ G. A. Gallup, K. Aflatooni, and P. D. Burrow, J. Chem. Phys. 118, 2562 (2003).

${ }^{5}$ J. Kopyra, J. Wnorowska, M. Foryś, and I. Szamrej, Int. J. Mass Spectrom. 268, 60 (2007).

${ }^{6}$ J. Kopyra, J. Wnorowska, M. Foryś, and I. Szamrej, Int. J. Mass Spectrom. 291, 13 (2010).

${ }^{7}$ E. I. Dashevskaya, I. Litvin, E. E. Nikitin, and J. Troe, Phys. Chem. Chem. Phys. 10, 1270 (2008).

${ }^{8}$ T. M. Miller, J. F. Friedman, L. C. Schaffer, and A. A. Viggiano, J. Chem. Phys. 131, 084302 (2009).

${ }^{9}$ O. J. Orient, A. Chutjian, R. W. Crompton, and B. Cheung, Phys. Rev. A 39, 4494 (1989).

${ }^{10}$ D. Smith, N. G. Adams, and E. Alge, J. Phys. B 17, 461 (1984).

${ }^{11}$ J. Kopyra, I. Szamrej, K. Graupner, L. M. Graham, T. A. Field, P. Sulzer, S. Denifl, T. D.Märk, P. Scheier, I. I. Fabrikant, M. Braun, M.-W. Ruf, and H. Hotop, Int. J. Mass Spectrom. 277, 130 (2008).

${ }^{12}$ S. J. Burns, J. M. Matthews, and D. L. McFadden, J. Phys. Chem. 100, 19436 (1996).

${ }^{13}$ K. M. Bansal and R. W. Fessenden, Chem. Phys. Lett. 15, 21 (1972).

${ }^{14}$ W. E. Wentworth, R. George, and H. Keith, J. Chem. Phys. 51, 1791 (1969).

${ }^{15}$ R. S. Wilde, G. A. Gallup, and I. I. Fabrikant, J. Phys. B 33, 5479 (2000).

${ }^{16}$ Z. L. Petrovic and R. W. Crompton, J. Phys. B 20, 5557 (1987).

${ }^{17}$ M. Braun, I. I. Fabrikant, M.-W. Ruf, and H. Hotop, J. Phys. B 40, 659 (2007).

${ }^{18}$ D. L. McCorkle, A. A. Christodoulides, L. G. Christophorou, and I. Szamrej, J. Chem. Phys. 72, 4049 (1980); 76, 753 (1982).

${ }^{19}$ R. S. Wilde, G. A. Gallup, and I. I. Fabrikant, J. Phys. B 32, 663 (1999).

${ }^{20}$ E. Alge, N. G. Adams, and D. Smith, J. Phys. B 17, 3827 (1984).

${ }^{21}$ K. Graupner, S. A. Haughey, T. A. Field, C. A. Mayhew, T. H. Hoffmann, O. May, J. Fedor, M. Allan, I. I. Fabrikant, E. Illenberger, M. Braun, M.-W. Ruf, and H. Hotop, J. Phys. Chem. A 114, 1474 (2010).

${ }^{22}$ J. D. Skalny, S. Matejcik, T. Mikoviny, and T. D. Märk, Int. J. Mass Spectrom. 223-224, 217 (2003).

${ }^{23}$ D. Smith, C. R. Herd, and N. G. Adams, Int. J. Mass Spectrom. Ion Process. 93, 15 (1989).

${ }^{24}$ D. Klar, M.-W. Ruf, I. I. Fabrikant, and H. Hotop, J. Phys. B 34, 3855 (2001).

${ }^{25}$ T. M. Miller, J. F. Friedman, J. S. Williamson, L. C. Schaffer, and A. A. Viggiano, Rev. Sci. Instrum. 80, 034104 (2009).

${ }^{26}$ D. Smith and P. Spanel, Adv. At. Mol., Opt. Phys. 32, 307 (1994).

${ }^{27}$ R. W. Fessenden and K. M. Bansal, J. Chem. Phys. 53, 3468 (1970).

${ }^{28}$ W. Domcke, Phys. Rep. 208, 97 (1991).

${ }^{29}$ I. I. Fabrikant, J. Phys. B 27, 4325 (1994).

${ }^{30}$ D. M. Pearl, P. D. Burrow, I. I. Fabrikant, and G. A. Gallup, J. Chem. Phys. 102, 2737 (1995).

${ }^{31}$ G. A. Gallup, S. I. Mamatkulov, and I. I. Fabrikant (unpublished).

${ }^{32}$ L. G. Christophorou, Z. Phys. Chem. 195, 195 (1996).

${ }^{33}$ J. M. Van Doren, T. M. Miller, A. A. Viggiano, P. Španěl, D. Smith, J. C. Bopp, and J. Troe, J. Chem. Phys. 128, 094309 (2008).

${ }^{34}$ C. A. Mayhew, A. D. J. Critchley, D. C. Howse, V. Mikhailov, and M. A. Parkes, Eur. Phys. J. D 35, 307 (2005).

${ }^{35}$ T. M. Miller, A. A. Viggiano, W. R. Dolbier, T. A. Sergeeva, and J. F. Friedman, J. Phys. Chem. A 111, 1024 (2007).

${ }^{36}$ T. M. Miller, J. F. Friedman, C. M. Caples, J. M. Van Doren, M. F. Bardaro, Jr., P. Nguyen, C. Magee, and A. A. Viggiano, J. Chem. Phys. 132, 214302 (2010).

${ }^{37}$ M.-W. Ruf, S. Barsotti, M. Braun, H. Hotop, and I. I. Fabrikant, J. Phys. B 37, 41 (2004).

${ }^{38}$ J. F. Friedman, T. M. Miller, L. C. Schaffer, A. A. Viggiano, and I. I. Fabrikant, Phys. Rev. A 79, 032707 (2009). 